\title{
ALONSO QUIJANO, \\ EL HIDALGO DE ALDEA
}

(Sobre el primer capitulo del Quijote)

\section{Cuillermo de la Cruz-Coronado \\ Universidade do Paraná}

\section{PóRTICO}

No es ésta la primera vez que en mi vida he tratado de Cervantes y del Quijote; pero sí es la primera que me decido a escribir sobre la obra inmortal. La atracción abismal, que la novela ejerce sobre todo lector, más o menos asiduo, es un fenó meno general; el Quijote es un abismo que atrae, que fascina, que moviliza la voluntad, el entendimiento y la pluma de una manera irresistible. Ahí está ese hecho incontrovertible de ser él la obra puramente humana más leida y a la vez la más comentada. Apenas hay persona avezada al manejo de la pluma, en cualquier latitud, que no haya echado su cuarto de espadas sobre el Quijote, aunque no sea más que en un artículo de cuatro perras.

Esto acobarda al más osado; mas el libro gana tan fuertemente nuestra voluntad, se nos entra tan profundamente en el alma, que es difícil sustraerse al cosquilleo de la tentación de decir nuestra palabra sobre él. El Quijote causa una fascinaciòn que nunca desengaña: cuanto más penetramos en su fondo, más sentimos cómo sus perspectivas se agrandan en anchura y en profundidad. El Quijote nunca nos engaña, nunca nos da esa sensación de vacío o de cansancio que, al menos en ciertos momentos críticos, experimentamos aun ante la obra literaria más valorada. El Quijote no es una obra "clásica", una de esas obras clásicas de ideas y contenidos tajados y precisos, cuyos limites, una vez 
alcanzados por nuestra mente, se estabilizan para nosotros como los de una pieza de perfección plástica; el Quijote es una obra que, además de lo que realmente nos dice, nos está sugiriendo siempre algo más, y estas sugerencias son de una riqueza inagotable; el Quijote no es una estatua clásica, sino una cantera de la cual cada uno arranca su propia estatua.

Para mí últimamente el "Curso de Extensão Universitária" sobre "El Nacimiento del Quijote y de D. Quijote" que he dado en la Universidad del Paraná, me ha obligado a concentrar y concretar algunas de las sugerencias que han ido bordando, desde antaño, mi lectura del Quijote. Pero he visto que es excesivamente pequeño el espacio de un curso especializado para todo lo que querríamos decir sobre el asunto; éste, a medida que intentábamos cercarlo, se nos desbordaba, se nos dilataba con una facilidad que era nuestra desesperación y nuestro gozo (1).

Una parte de ese curso - El Nacimiento de D. Quijote es la base de estos artículos cuyo propósito no abarca más allá de un comentario al primer capítulo de la obra. Dejo bien clara esta limitación que voluntariamente impongo a mi trabajo en su comienzo, para que no se me exija más que lo que ese primer capítulo dé de sí para los dos temas que he querido desentrañar: El Hidalgo de Aldea y El Caballero Andante.

Siempre que me ocupo del Quijote, se apodera de mí un sentimiento complejo de grande gozo y de no escaso temor; pero mientras el temor se circunscribe a la parte racional de la mente, y siempre por motivos externos, el gozo se difunde y empapa todo el ser y por razones del todo intimas. Se trata, a todas luces, de una situación psíquica de paradoja cuya explicación hay que buscar en esa tremenda y maravillosa paradoja que es el Quijote como obra literaria $y$, sobre todo, como reflejo espiritual de la vida humana en su conjunto. El Quijote es el libro más accesible a la comunicación, al comentario manual, el más fácil de comprender con los conceptos más sencillos, hasta con el menor bagaje de cultura, porque una buena parte de su contenido está

(1) Duró este "Curso de Extensão Universitária" sobre "El Nacimiento del Quijote $y$ de D. Quijote" del 25 de Octubre al 7 de Noviembre de 1954. 
tocando la piel de nuestro propio ser, está flotando a sobrehaz de la más simple de las vidas humanas. Ello explica por qué han sido los personajes principales de la obra - D. Quijote y Sancho - las dos creaciones literarias que más han penetrado en la entraña de todos los pueblos, tal vez los únicos de popularidad universal en ei tiempo y en el espacio (2). El dúo D. Quijote - Sancho, un carácier y una creación única en dualidad, están ya para siempre, y cada vez más, compenetrados con el alma y con la imaginación de los pueblos de las más extrañas culturas; en todos se han hecho simbolo que anda por sus calles como si cada pueblo lo hubiese creado por sí mismo. Este hecho revela la capacidad de adaptación de la obra a todos los ambientes, y la facilidad que esos ambientes encuentran para asimilársela y apropiársela.

Pero a la vez el Quijote es el libro más difícil de ser abarcado en su integración, porque otra parte suya toca las raíces más hondas de nuestra alma; y sólo espíritus señeros consiguen dar con sus propias raices y vivir desde ellas.

De ahí ese resultado real, y aparentemente paradójico, de ser el Quijote un libro tan amado por la gente sencilla y al mismo tiempo tan manejado en las altas elucubraciones de la mente. El Quijote está siempre y con la misma fuerza en los polos de la cultura y sus intermedios, en todas las capas de la sociedad y de la historia, sin duda por no ser él un libro para la cultura, sino un libro que, so capa de divertimiento o entretenimiento, va destinado a la humanidad, para su vida, no para su entendimiento; libro para toda la humanidad, porque a ca-

(2) "D. Quijote, Sancho, D. Juan, Hamlet y Fausto son los cinco grandes hombres creados por el hombre. A semejança de lo que acontece con los grandes hombres que hizo directamente el Creador, su figura se cubre a cada generación de una floración de leyendas, opiniones, interpretaciones y simbolos", dice Salvador de Madariaga en su "Guía del lector del Quijote", capítulo $V$ "El verdadero D. Quijote", pág. 94. 4. edic. Editorial Hermes, Méjico - Buenos Aires, 1953.

Añado de mi cuenta que la amplitud de ambientes conquistados y de formas de vida de esos caracteres de hombres es de suerte muy distinta; Hamlet y Fausto, fuera de sus órbitas originarias, viven en zonas casi exclusivamente cultas, $y$, con verdadera comprensión, acaso sólo en atmósferas de cultura superior. D. Juan es el que va más al alcance en popularidad universal al dúo D. Quijote - Sancho, también él erigido en fábula y proverbio de las gentes mas sin sus dimensiones. Las expresiones simbólicas "ser uno un D. Quijote - un Quijote, un Sancho, un D. Juan" existen ya en las más de las lenguas cultas; no se da otro tanto, que sepamos, con Hamlet o Fausto. 
da porción de ella trae él su mensaje (3); mensaje general y mensaje específico, que sólo él, sólo el Quijote, ha sabido mantener y multiplicar con las generaciones que lo han leído y lo han amado (4).

No han faltado errores y falsificaciones en esta proyección que del Quijote han hecho las gentes sobre su propia existencia; mas esto no tiene mayor importancia para la obra en si, aunque siempre salga perdiendo de tales mixtificaciones, algunas surgidas con un afán, bien comprensible, de realzarla. Nada de eso monta efectivamente en la proyección histórica del Quijote; lo de monta es el hecho, el fenómeno histórico, de ver a todas las épocas, a todas las gentes, sumergirse en el Quijote y leerlo como quien lee la historia de su propia alma. Por muy disparatado que

(3) Confírmase esta idea con la existencia de las ediciones escolares del Quijote; otras obras de valor universal las tienen igualmente, pero ninguna con la profusión del Quijote. No sólo en España y países de habla española, donde tantos hemos aprendido a leer en el Quijote; otras naciones, muy alejadas del área cultural hispánica, enseñan o enseñaron a sus hijos a leer en traducciones escolares de la novela. Cito el caso de Estonia, de antes de la actual absorción comunista, recogido de expatriados de aquella nación báltica: pero podría agregársele el de muchas otras naciones cultas. Para el Brasil mencionemos siquiera la labor, de estilo personal, de Monteiro Lobato en su Dom Quixote para crianças.

En los últimos años se ha querido combatir en España a estos Quijotes escolares a pretexto de salvaguardar al propio libro. Se dijo que muchos niños, obligados a leer sobre un texto que no comprendian, le cobraban tirria para siempre, incapacitándose para releerlo más tarde, cuando podrían entenderlo y amarlo. La solución a este problema, que es cierto pero exagerado, no debe ser la eliminación del Quijote de las escuelas primarias, sino la preparación de ediciones verdaderamente escolares, adaptadas a la mentalidad de los niños; en ellas, a más del expurgo de pasajes escabrosos, como suele hacerce, sería necesaria la acomodación de otros de contenido superior a su alcance. Sin tanto cuidado, muchos hemos leido por primera vez el Quijote entre los 7 y los 10 años en edición de letra menuda, para adelantados en la escuela, y, en las mismas barbas de nuestros temibles maestros (tiempos de la palmeta y de la vara de olivo!) hemos celebrado las aventuras y desventuras del hidalgo con risas mal contenidas, que es la primera iniciación al hondo sentido del libro.

Lo que interesa destacar en esta nota es que esos Quijotes escolares, que acercan al alma del niño el dúo inmortal, comprueban la realidad de una cre. encia, de nuestra conciencia de mayores, en un mensaje de la novela cervantina hasta para la primera edad.

(4) Subrayo el hecho de ser el Quijote una de las poquisimas obras literarias de abolengo clásico y de época moderna, que no ha sufrido crisis de prestigio desde su nacimiento. No ha ocupado siempre, claro está, la misma cima de estimación, que no es posible, pero nunca ha pasado por esas noches oscuras de olvido y aun menosprecio por que han tenido que pasar casi todos los otros, Dante y Shakespeare entre ellos, hasta asomarles la luz de nuevas auroras. En el Quijote la línea de estimación ha sido siempre progresiva y ascen- 
sea en determinados momentos, este fenómeno coloca al Quijote por encima de cualquiera otra obra literaria meramente humana.

$\mathrm{Ni}$ es eso todo. Ocurre que esta variedad de mensajes, que el Quijote trae para épocas históricas tan diferentes, para caracteres personales tan opuestos, para culturas tan inconformables, se transmite según una ley dialéctica de forma casi idéntica en cada uno de nosotros, de los que nos dedicamos a leerlo a conciencia y con amor. A través de las distintas etapas de nuestro vivir, de las varias fases de nuestra superación cultural, el Quijote nos va ofreciendo nuevas perspectivas para la vida y para la cultura, la nuestra y la ajena; nuevos rincones que se iluminan; pensamientos antiguos de que, de pronto, tenemos conciencia llenándose de nueva claridad; sentimientos e ideas que se alargan hasta límites insospechados. Más aún; no sólo en las etapas esenciales de la vida. sino hasta en esas otras etapas más o menos transitorias, más o menos superficiales, pero siempre nuestras, que son los estados generales que se suceden en nuestra vivencia sentimental (tristeza, alegría; optimismo, pesimismo; impulso ascensional, sensación derrotista), el Quijote se nos pone siempre de nuestro lado como una voz amiga que salta de nosotros mismos. sugeridora de palabras en cuyo seno descubrimos el sentido más alto que tiene cada acontecer nuestro y ajeno; $y$ es en ese sentido más alto, en ese mundo total, donde descubrimos el verdadero valor de nuestro vivir cotidiano y particular,

dente hasta nuestros dias; los baches, si los hubo, son pequeños y carecen de significado para la valoración histórica esencial de la novela.

V. gr.: los ataques disparatados, que en el s. XVIII dirige a Cervantes el malhumorado Garcia de la Huerta, sólo le sirven para echar sobre si la burla de sus muchos enemigos y para hacer mas palmaria la admiración del siglo hacia la principal obra del alcalaino, ya entonces llamada a boca llena "inmortal". A los finales de la centuria la noble pluma de Cadalso puede abrir sin rebozo la Introducción de sus célebres Cartas Marruecas con esta frase: "Desde que Miguel de Cervantes compuso su inmortal novela". En el XVIII, con D. Vicente de los Rios en la primera mitad, y D. Juan Antonio Pellicer en la segunda, se inaugura la serie de los grandes quijotistas. El XVIII, sin duda subyugado por ese indefinible encanto secreto de la novela, suscita las sospechas de su sentido oculto: y el ocultismo trae de mano las interpretaciones; el mismo Cadalso cree atisbar segundas intenciones en el novelista al decir en la LXI carta marrueca: "no deja de mortificarme la sospecha de que el sentido literal es uno, y el verdadero es otro muy diferente". Esta es la contrapartida del XVIII frente al autor de L Raquel, que osó motejar a Cervantes de "inicuo satírico, denigrador, envidioso y enemigo del mérito ajeno." Y asi en toda la historia del Quijote $y$ de Cervantes ante cualquier desentonado. 
el valor universal que arrastra consigo el más pequeño acto del más pequeño de los humanos.

Aquí, en esta desvelación que nos hace el Quijote de nuestra particularidad en la universalidad, es donde se apoya ese dicho, que hoy tiene ya carta de naturaleza en la paremiología española, según el cual el Quijote, de jóvenes nos hace reir, de hombres nos hace pensar, y de viejos nos hace llorar. Al hombre maduro, típico representante de la más grave problemática, le hace pensar porque le agudiza, le pone delante atravesadamente sus propios problemas que son los de todo hombre; al joven, que no tiene problemática sino esperanzas, le ofrece la cara fácil de las cosas, y la risa, la carcajada, para los trances agudos cuya transcendencia todavía no se comprende; finalmente, al viejo, que tampoco tiene problemas sino desengaños, le da materia para la final resignación y le provoca la exteriorización sentimental del fracaso, las lágrimas. En realidad todos los hombres, salvo el santo, somos unos fracasados; por eso al final de la vida las lágrimas, si no más fáciles, son mucho más amargas.

Parte de nuestro temor al tratar del Quijote proviene de esta fluctuación con que la grande obra pasa por nosotros en distintos momentos de nuestra vida: si cada vez que vuelvo al glorioso libro, hallo nuevos campos de visión que se me otorgan graciosamente, también cada vez tropiezo con la necesidad de tener que rectificar interpretaciones anteriores. Y se levanta el fantasma de la desconfianza, de nuestra imposibilidad de hallar definitivamente el sentido total, todos los sentidos del Quijote, porque éstos se nos transforman constantemente. Un interrogante se nos clava entonces en la conciencia: lo que creemos encontrar en el Quijote, eso que a cada instante nos parece tan claro, visto desde la atalaya de una síntesis crítica, ¿ es realmente del Quijote o es de nosotros mismos? En vez de ser el Quijote, o al menos al mismo tiempo que lo es, un libro que nos da, que nos entrega nuestra propia conciencia, ¿ no será un libro al que nosotros damos, que nos sirve de reflejo o espejo de nuestra vida?

En este interrogante se oculta el último problema para un lector asiduo del Quijote, problema que muchos cervantistas pasan tranquilamente por alto porque no lo ven. Su ceguera ha origi- 
nado, a mi entender, esa serie de protestas contra las inteipretaciones del Quijote; protestas vanas en el fondo, en muchos casos, porque, si es cierto que el Quijote no tiene, no puede tener tantos sentidos, a menudo contradictorios, como se le atribuyen, tampoco es dudoso que esos sentidos, no todos, están esencialmente en él porque sólo él ha sido capaz de suscitarlos en nosotros. El valor real de una obra está menos en lo que dice que en lo que ella nos obliga a decirnos a nosotros mismos, en lo que nos despierta, en lo que arranca de nuestra propia inmanencia: (naturalmente excluímos el caso de ciertos intérpretes que hacen del Quijote un pretexto para sus extravagancias de pensamiento convirtiéndolo en un vehículo que los prestigie $y$ que los enmascare para el público inocente; no son ésas interpretaciones, sino cosa bien diferente). $Y$ ved el gran secreto del Quijote, el que lo mantiene vivo y operante en todas las épocas de la humanidad y en todas las edades de cada hombre: el que a cada época, a cada hombre, a cada edad del hombre, le descubre, o cuando menos le da la oportunidad de descubrir, su propio sentido: en esto radica la inmortalidad del Quijote ante los pueblos.

Otra sombra me pone temor cuando hablo del Quijote a no especialistas: la sombra de un Quijote falsificado que es el más conocido porque es un Quijote extremadamente simplificado. Corre por ahi, elaborado por la imaginación popular, un Quijote que no es el cervantino sino una estilización unilateral del mismo: un tipo alto, desmedidamente delgado, casi descarnado, en estirada vertical, unidimensional. $Y$ en contraste, en excesivo contraste, un Sancho bajete, regordete, rechoncho, en aplastamiento horizontal, también unidimensional. Los dos tipos esenciales de la obra se han estilizado en sentido cruzado, se han exagerado en oposición; y para remate, a esta estilización física, como era de esperar, se la ha llenado de un contenido simbólico, de eso que, sin entenderlo bien, se llama el hombre idealista y el hombre realista, el hombre abstracto y el hombre positivo. Mas los tipos creados por Cervantes no son símbolos, ni tampoco puros caracteres; son tipos intermedios entre el símbolo y el carácter, resumiendo a ambos, con el valor universalizable que encierra el símbolo, y al mismo tiempo con los matices y curvas que con- 
tiene un carácter. EI D. Quijote que sale de la pluma de Cervantes tiene muchos puntos de contacto con su escudero Sancho, así como Sancho tiene mucho (y gana más al desenvolverse la obra) de su señor D. Quijote. Se da en Cervantes una interferencia o entrecruce de recorridos en dirección de encuentro de sus dos personajes, y tal, que no es aventurado decir que el que comenzó siendo D. Quijote, puro idealista, en el primer capítulo, acaba siendo en el último tan realista como el Sancho primitivo; e inversamente, el que empieza siendo un elemental Sancho Panza, va despojándose poco a poco de su exceso de carnes hasta acabar tan perdidamente idealista, tan desahuciadamente caballeresco como el primario D. Quijote. Valga este detalle: en el último capitulo de la novela $D$. Quijote se torna cuerdo, renuncia y abomina de los libros de caballerías y hasta se confiesa como pecado de las locuras hechas por el caballerismo; Sancho, en cambio, se desespera al oirle hablar asi, le reconviene, intenta reanimarlo con la sugestión de que todavia pueden desencantar a Dulcinea. D. Quijote al final se reduce a lo que era, un bueno y honrado hidalgo de aldea llamado Alonso Quijano y apellidado "el Bueno" (5) y no quiere oirse llamar más de D. Quijote de la Mancha; Sancho no vuelve a ser en sus adentros un labrador aldeano; al rematar la obra, Cervantes lo deja soñando con su escudería. Indubitablemente, D. Quijote, que es el que transmite a su escudero la locura, acaba siendo mucho más realista

(5) En el capítulo final del Quijote, al despertar del sueño en que recobró la cordura, dice Cervantes: "Apenas los vió D. Quijote (al cura, al bachiller $y$ al barbero, sus amigos), cuando dijo: Dadme albricias, buenos señores, de que ya yo no soy D. Quijote de la Mancha, sino Alonso Quijano, a quien mis costumbres me dieron renombre de Bueno. Ya soy enemigo de Amadís de Gaula y de toda la infinita caterva de su linaje, ya me son odiosas todas las historias profanas de la andante caballeria: ya conozco mi necedad y el peligro en que me pusieron haberlas leido; ya, por misericordia de Dios, escarmentando en cabeza propia, las abomino". En la página siguiente vienen los lamentos y la resistencia de Sancho, todavía tocado de la ilusión y aun de la locura: "Ay! No se muera vuesa merced, señor mio, sino tome mi consejo y viva muchos años... Mire no sea perezoso, sino levántese desa cama y vámonos al campo, vestidos de pastores, como tenemos concertado; quizá tras de alguna mata hallaremos a la señora Doña Dulcinea desencantada, que no haya más que ver". La réplica de D. Quijote, pese a la intercesión del bachiller, es rápida y de una tristeza definitiva: "Señores - dijo D. Quijote - vámonos poco a poco, pues ya en los nidos de antaño, no hay pájaros hogaño. Yo fuí loco, y ya soy cuerdo: fuí D. Quijote de la Mancha, y soy agora, como he dicho, Alonso Quijano el Bueno". 
que éste, que, subido por la ambición de la ínsula al cielo caballeresco, ya no sabe cómo apearse de él. Con toda razón se ha podido hablar de una sanchificación de $D$. Quijote y de una quijotización de Sancho (6).

El recelo del que quiere hablar del verdadero Quijote, el literario, el cervantino, es el de tener que desengañar a su público de ese Quijote callejero, estilizado, ese mito del contraste donde los dos tipos se han ido distanciando cada vez más a punto de convertirse en símbolos opuestos. A la postre esos mitos tienen también su razón de ser, están parcialmente motivados por el mismo Cervantes que fué el que los echó a andar en contraste inicial, aunque luego les rectificase los caminos; además es ésa la única manera de que sean comprendidos por la mayoría de los hombres que no saben de las matizaciones literarias que el tipo cervantino contiene.

El primero del Quijote es un capítulo bipartido; dos tiempos se lo reparten: la presentación del personaje en su condición real, y la evolución del mismo a héroe de la novela mediante la locura caballeresca. Cervantes sigue los pasos de su criatura en estos dos estados, insinúa motivos, resalta pormenores, señala lances y tránsitos: no lo hace de manera estudiada y lógica, sino que, como auténtico artista, se abandona a un bello desorden en el que no es dificil recoger el esquema y rehacerlo con toda nitidez. Cervantes no hizo una obra científica, cualquiera que ella sea, síno una obra de creación literaria, de valores esencialmente poéticos; cabe a los críticos esa labor de reestructuración; en ella nos vamos a emplear humildemente.

En ese primer capítulo nace el alma del héroe en su integridad, que es decir también en su contradicción, en su contraste: el alma del personaje, que es a un tiempo Alonso Quijano y D. Quijote de la Mancha, es un alma en choque consigo misma; en este choque se sale de sí, enloquece, y pone en marcha la novela. Los dos planos esenciales, el real y el imaginario, la hidalguía y la caballería, derivan uno del otro dentro de una lógica admira-

(6) Salvador de Madariaga: Obra y edic. cit., caps. VII y VIII, págs. $127-148$. 
ble; $\sin$ hidalgo no habría caballero, y sin caballero andante no habría novela.

Nuestro estudio quiere ceñirse a estas dos fases del héroe en su presentación inicial: El Hidalgo de Aldea y El caballero Andante.

El desarrollo del primero sigue las líneas de este esquema:

1) Coordenadas históricas del hidalgo

II) Los símbolos del hidalgo.

III) Círculo familiar y vida cuotidiana.

IV) Personalidad de Alonso Quijano. 


\title{
COORDENADAS HISTÓRICAS DEL HIDALGO.
}

\author{
"En un lugar de la Mancha, de cuyo nombre no quiero acor- \\ darme, no ha mucho tiempo que vivia un hidalgo..."
}

Con estas dos líneas, que abren el Quijote, traza Cervantes las coordenadas históricas o circuntancias del héroe en su estado primario. El acierto de Cervantes en ese comienzo es uno de tantos aspectos que aproximam particularmente su obra a nuestro tiempo, preocupado por los problemas de la historicidad del hombre.

El hombre no es sólo lo que es como tal, como pura esencia de humanidad; ésta nunca se nos da desamparada y abstracta, sino encuadrada en unas circunstancias vitales que, aunque accidentales al hombre como tal, no lo son a la personalidad concreta del hombre que circunscriben. Cada personalidad humana histórica consta de esa humanidad esencial que señalaba la filosofía clásica y de la que tenemos conciencia autónoma, y de esos elementos que han entrado a formar parte de ella en un determinado periodo histórico, en un determinado lugar y en una determinada clase social. El hombre no nace simplemente; al nacer ya tiene una serie de determinantes dentro de los cuales él debe desenvolver su individualidad. Es lo que debe entenderse cuando se dice que el hombre es un ser histórico, el único ser histórico, porque nace arraigado a unas determinantes históricas que obran sobre su futura personalidad y sobre las que él mismo tendrá que obrar para crearse una personalidad original.

Hoy, para nuestra conciencia histórica, estos conceptos son simplicísimos y de fácil aceptación; existían, sin duda, en el pensamiento de los siglos pasados, pero ha sido nuestra época la que ha subrayado este aspecto del hombre, la que se lo ha propuesto 
de una manera obsesionante, haciéndolo formar parte de nuestro ambiente cultural (7).

No sucedía así en tiempo de Cervantes; por eso resulta sorprendente y genial que su glorioso libro comience poniéndonos delante esas circunstancias de su héroe, lo que llamamos las coordenadas históricas del mismo: tiempo, espacio y sociedad.

Cervantes prepara muy bien la introducción del futuro héroe que llamará D. Quijote de la Mancha; empieza dándonos al hombre real (Alonso Quijano) y a éste nos lo encaja históricamente dentro de las circunstancias de espacio, tiempo y sociedad: he aquí el trazado de esas coordenadas:

\author{
Espacio: "En un lugar de la Mancha..." \\ Tiempo: "no ha mucho tiempo que vivía" \\ Condición Social: "un hidalgo de los de..."
}

\title{
1) EL ESPACIO ORIGINAL DEL hIDALCO.
}

\section{1.') "En un lugar de la Mancha"}

D. Quijote nace en un lugar de la Mancha. Está fuera de toda posibilidad el nacimiento del Quijote (la obra) en un lugar manchego: en cambio, es indudable que D. Quijote (el personaje) sí nació en la Mancha, en un lugarejo de ella, en una aldea. La partida de nacimiento del héroe es lo primero que hace Cer-

(7) Es falsear la persona humana el intento de una filosofía del hombre sin encarar su historicidad; la filosofía clásica, griega y escolástica, no despreció esa faceta que está latente en su pensamiento, aunque de manera embrionaria. Mas es la filosofía más próxima a nosotros la que ha traido esa consideración a primer plano en la metafísica del hombre, no raramente con prejuicio de la atención debida a su esencia metafísica propiamente dicha. El peligro que una desatención así supone, es mucho más grave, porque vacía de contenido básico al propio tema de la historicidad y reduce al hombre a un ser en devenir puro, ser exclusivamente histórico, que, por lo mismo, sólo podrá ser definido en el instante de su muerte, como pretenciosamente ha querido Sartre. Las consecuencias nefastas de esa reducción están a la vista en todas las iilosofías contemporáneas en que la metafísica se ha esfumado como un fuzgo fatuo o se ha enmascarado en ondulaciones marginales, a veces interesantes y llenas de calor humano, pero las más veces desfondadas y a merced de cualquier nuevo soplo de opinión, cuando no declaradamente deturpadoras de to más hondo del hombre que se les escapa enteramente. 
vantes: mas no es demasiado explícito: deja en silencio el nombre del lugar. Cuál fué ese lugar?

Muchos son los lugares de la Mancha que se han atribuido el nacimiento del hidalgo manchego: la mayoría se funda en una falsa asociación del lugar donde se escribió la obra (marcado en la frase "engendrado en una cárcel") (7a), y el lugar del nacimiento del personaje ("Iugar de la Mancha") relacionándolas a ambas a través de la expresión "de cuyo nombre no quiero acordarme" interpretada con un significado sentimental de resentimiento $y$ venganza del autor. La asociación de esas dos expresiones carece de toda objetividad histórica, y nos confirmamos en ello al entender el significado obvio y sencillo de la frase que se ha tomado como clave de esa ligazón, "de cuyo nombre no quiero acordarme": esa frase parece no encerrar ninguna alusión sentimental y por tanto cae por tierra toda la argumentación construida sobre la misma.

Una interpretación objetiva de los textos cervantinos quiere señalar a Argamasilla como el lugar de la Mancha de D. Quijote; se asegura así conjeturando que "los académicos de la Argamasilla, lugar de la Mancha" que escribieron sus epitafios y sonetos "en vida y muerte de D. Quijote de la Marcha", inventados burlonamente por Cervantes al final de la primera parte, eran patricios del héroe, $y$ al emplear sus plumas en éste, lo hicieron para enaltecer el lugar de nacimiento, común a ellos y a él. De ser cierta esta conjetura, es innecesario advertir que esa Argamasilla es la de Calatrava, único lugar que con tal nombre existía en la Mancha en tiempo de Cervantes.

La cuestión para mi no está definitivamente resuelta como para alejar toda duda sobre las intenciones de Cervantes respecto al lugar del nacimiento de D. Quijote. Es posible que el escritor hiciese argamasillescos a los académicos por la necesidad de localizar de alguna manera a la fingida Academia poética; mas sin que eso implicase una determinación local para su héroe.

(7a) La célebre frase se halla en los comienzos del prólogo del primer Quijote: "Y asi, $c$ qué podria engendrar el estéril y mal cultivado ingenio mio, sino la historia de un hijo seco, avellanado, antojadizo y lleno de pensamientos varios y nunca imaginados de otro alguno, bien como quien se engendró en una cárcel, donde toda incomodidad tiene su asiento $y$ donde todo triste ruido hace su habitación?" 
Al poner Cervantes vagamente, indeterminadamente, "en un Iugar de la Mancha", pudo muy bien tener la intención expresa de no señalar ningún lugar manchego concreto como patria de D. Quijote, antes dejarlo a la fantasía de los lectores, los cuales efectivamente, en los tres siglos y medio de vida literaria del personaje, han ido de un lado para otro de la Mancha buscándole los pañales; y no los han encontrado incontrovertiblemente.

En efecto: hay un pasaje en el capítulo final del Quijote, ya a los finales del mismo, en que Cervantes, como quien preveía esas idas y venidas de los futuros quijotistas, declara abiertamente que no quiso puntualizar ningún lugar manchego como siendo el de D. Quijote, para que éste siguiera en la literatura la misma suerte que en la historia el autor de la Odisea: "Este fin tuvo el Ingenioso Hidalgo de la Mancha, cuyo lugar no quiso poner Cide Hamete puntualmente, por dejar que todas las villas y lugares de la Mancha contendiesen entre sí por ahijársele y tenérsele por suyo como contendieron las siete ciudades de Grecia por Homero" (8). El paralelismo de contraposición de estos dos pasajes del Quijote (los únicos que, fugaz pero expresamente, tratan de la patria del personaje, uno en el principio como partida de su nacimiento literario, $y$ otro en el final como acta de su defunción, uno y otro en los dos extremos de la obra) legitima la idea de aproximarlos y explicar el uno por el otro. Como en el segundo pasaje es palmaria la intención de Cervantes de dejar en el aire la puntualización del lugar del héroe dentro de la Mancha, tal vez sea licito pensar que ésa fué también su intención en el primero de los pasajes referidos; no se trataría así de ocultar ningún lugar cierto con la frase vaga "en un lugar de la Mancha, de cuyo nombre no quiero acordarme", sino que

(8) Capítulo final del Quijote. No "todas las villas y lugares de la Mancha", pero sí varias de ellas, y otras de fuera de la región, han acudido a la cita de Cervantes para "ahijarse" a D. Quijote; hasta nueve se han contado, dos más que las que contendieron por Homero: Argamasilla a secas, Argamasilla de Alba, Miguel Esteban, Viliaverde, Tirteafuera, Quintanar de la Orden, Argamasilla de Calatrava, Esquivias y España en general. Es curioso constatar que los lugares que se disputan al propio Cervantes son también nueve: Sevilla, Toledo, Esquivias, Madrid, Lucena, Consuegra, Alcázar de San Juan, Córdoba y Alcalá de Henares que se ha llevado definitivamente la palma.

Conf. Luis Astrana Marín: "Vida ejemplar y heróica de Miguel de Ce:vantes Saavedra", T. IV, pág. 24. Instituto Editorial Reus, Madrid, 1952. En la nota de la página citada puede consultarse la bibliografía sobre este punto. 
esa expresión significaría sencillamente lo que suena; que Cervantes no quiso señalar con exactitud el lugar de su personaje, como lo dice expresamente en el segundo pasaje. Nada, pues, de ocultismo intencionado, sino simple indeterminación. Ello explicaría hasta cierto punto las incongruencias que salen a cada paso en la novela sobre la geografía de la Mancha; no habiendo querido puntualizar ningún lugar, sino la región, la exactitud geográfica hubiera traicionado a Cervantes, porque por ella hubiéramos nosotros hallado a la larga exactamente la patria de D. Quijote; él, para confusión de los investigadores, contribuyendo a ello su ignorancia de la geografía manchega, se dejó llevar libremente del sonido de los nombres sin temor a errores geográficos y siguiendo una guía de nombres de posición incierta porque los tenía sólo de oídas.

No se me escapa que puede rechazarse esta opinión por confundir, al parecer, las perspectivas de creación de los dos pasajes; desde luego la visión de Cervantes en la creación del Quijote sigue una trayectoria ascensional de la que ese comienzo, que es el primer pasaje comentado, es el punto de partida, y el otro es el de arribada; desde el arranque episódico del principio del Quijote hasta la visión universalista del final se ha recorrido mucho camino en los intentos y en las realizaciones del Cervantes quijotista. En su síntesis poderosa del segundo Quijote bien pudo Cervantes permitirse esa indeterminación del "lugar de la Mancha" porque favorecia el sentido último, más profundo, de su obra, la universalidad, la liberación de tiempo y espacio concreto; por el contrario, es probable que Cervantes no pensara del mismo modo al redactar las primeras líneas del primer Quijote, nacido con pretensiones minoritarias; consiguientemente acaso más que de una indeterminación a propósito, se trate en esas líneas de un simple ocultismo de nombre previamente escogido pero simulado, como recurso literario, durante toda la obra, luego aparecido en los versos finales del primer Quijote en la forma burlesca de la academia argamasillesca. La cita de Argamasilla en la conclusión del primer Quijote puede tormarse, si se quiere, como argumento del lugar que Cervantes ocultó en el principio del mismo; pero nótese bien que él no se manifestó claramente, ni ligó "Argamasilla, lugar de la Mancha" 
con "lugar de D. Quijote". Esta vaguedad, en que se deja en el primer Quijote el lugar del héroe, la aprovechó Cervantes en el segundo Quijote para la abstracción desligando ya de propósito a D. Quijote de cualquier lugar fijo de la región, y quedando él así, como dice su nombre caballeresco, por hijo de toda ella, de toda la Mancha, que es su verdadera patria(9).

Por lo demás es sabido que esa introducción, "en un lugar de la Mancha", no es originaria del Quijote aunque por él haya alcanzado todas las fronteras; la expresión aparece por primera vez en un romance que trae el Romancero General de 1.600, y que dice:

$$
\begin{aligned}
& \text { Un lencero portugués } \\
& \text { recién llegado a Castilla, } \\
& \text { más valiente que Roldán } \\
& \text { y más galán que Macias, } \\
& \text { en un lugar de la Mancha, } \\
& \text { que no le saldrá en su vida, } \\
& \text { se enamoró muy despacio } \\
& \text { de una bella casadilla. }
\end{aligned}
$$

No es ésta la única vez que Cervantes encabeza un capitulo con un verso: el capítulo noveno de la segunda parte se abre con el primer verso del famoso romance de Conde Claros:

\section{Media noche era por filo;}

el capítulo $X X V I$ de esa misma parte comienza con el primer verso del Canto II de la Eneida ("Conticuere omnes intentique ora tenebant") según la traducción de Gregorio Hernández de Velasco (Amberes, 1557):

\section{Callaron todos, tirios y troyanos.}

Cervantes usó el mismo recurso en el principio del Quijote y pudo hacerlo con tanto más derecho cuanto que ese romance, de que toma el verso, bien puede ser de su propiedad, tal vez uno de esos romances de que él se gloría haber compuesto en el capítulo IV del "Viaje del Parnaso":

(9) Más adelante hacemos referencia a la opinión de Astrana Marín que interpreta la frase entera como una manera reforzada de desviar el pinsamiento del lector, del verdadero lugar de $\mathrm{D}$. Quijote, que seria Esquivias. 
Yo he compuesto romances infinitos (verso 37);

al menos en la paternidad cervantina de este romance se funda parcialmente una opinión, que enseguida traemos a cuento, según la cual el Quijote nace como una sátira del exaltado erotismo de su enemigo Lope de Vega.

\section{9) ". . de cuyo nombre no quiero acordarme".}

Cuál es el sentido verdadero de esta frase? Discutidisimo ha sido; a tres grupos podemos reducir las opiniones:

a) La de los que interpretan la frase como una expresión sentimental alusiva a sufrimientos pasados por Cervantes en "un lugar de la Mancha": hoy esta teoría, sea cualquiera el lugar manchego preferido, está descartada por la mejor crítica quijotista: carecemos del más pequeño pormenor que ligue sentimental o dolorosamente la vida de Cervantes a la región de la Mancha; no tenemos, pues, argumento para interpretar la frase cervantina sobre el lugar manchego como una evasión en el recuerdo por motivos dolorosos, y a la vez como una venganza literaria de los mismos.

b) Otra interpretación sentimental no se ciñe a recuerdos tristes de un lugar manchego sino de la persona de su rival Lope de Vega; relaciona con el núcleo inicial del Quijote (del que deseo escribir pròximamente) tanto el "Entremés de los Romances" como el romance antes citado "Un lencero portugués". A las tres obras - romance, entremés, novela - les dan el mismo autor (Cervantes), la misma intención (la burla del enamoradizo Lope), y la misma interpretación (una contrafigura de la vida de Lope, y de las personas y cosas unidas a sus amores). Desde luego parte de la sátira del Entremés cae muy bien a Lope que, cuando se enamoraba - y era harto frecuente - , se desahogaba con romances amorosos, entre otras cosas; igualmente el romance puede ser una clave de los amores de Lope, particularmente de los adulterinos con Micaela Luján (10). Aun es más fuerte la argumen-

(10) Justo Carcia Soriano: "Los dos D. Quijote", Toledo, 1944. Justo Carcia Soriano y Justo García Morales: "Guia del lector del Quijote", Prologo a la edic. del Quijote en la col. "Joya" de la Ed. Aguilar, Madrid, 1951, págs. 22-23. Para que se vea hasta qué punto el romance alegado es clave de alu- 
tación en pro de la depedencia del primer Quijote de la relación Lope - Cervantes y Lope - Micaela: tenemos el hecho cierto de que Cervantes concibe el primer Quijote y comienza a redactarlo en la cárcel sevillana, en 1602; esa fecha coincide con la estancia de Lope en Sevilla a la que llega siguiendo los pasos de su amada Micaela (Camila Lucinda) y en la que es agasajado por los círculos culturales de la ciudad; este contraste, entre el rival escandaloso homenajeado $y$ su propia vida inocente arrastrada en una cárcel, pudo ejercer sobre el ánimo de Cervantes una presión creadora, de la que salió el núcleo inicial del Quijote como un episodio de venganza personal.

Pues bien; según esta triple alusión lopesca se interpreta la frase "de cuyo nombre no quiero acordarme" como una repugnancia de Cervantes a recordar lugares y cosas aproximados a la vida escandalosa de su enemigo, al que, por otra parte, intentaba zaherir.

c) La opinión más ceñida al texto y, por lo mismo, la más legítima, es la del maestro Rodríguez Marín; para él no hace falta una interpretación; basta la simple explicación del significado de la oración apoyada en la misma lengua, en su gramática y en su historia, y confirmada como recurso literario.

Primero: querer más infinitivo significa en español estar a punto de. estar próximo a; los ejemplos abundan desde la literatura medieval ("Media noche era por filo / los gallos querían cantare" del romance del Conde Claros) hasta expresiones actuales (como cuando decimos de una persona o cosa que estamos a punto de reconocer: "quiero recordarla", "quiero reconocerla...").

siones a Lope, párese mientes en estos detalles: Lope era hijo de un bordador ("lencero"?) montañés, que había venido a la corte tras una aventura amorosa y que, seguido por los celos de su esposa, se reconcilia con ella siendo Lope el fruto de la reconciliación ("recién llegado a Castilla" ?); Lope de Vega mostraba predilección por temas portugueses ("portugués" ?), había sentado flaza de soldado y luchado ("más valiente que Roldán" ?), estaba siempre enredado en amores que fluian a su pluma en toda clase de versos ("y más galán que Macías" ?); en 1602, va a Sevilla tras su amada Micaela que era casada ("una bella casadilla" ?) y natural de un pueblecito de Sierra Morena, acaso El Viso del Marqués, en los bordes de la Mancha ("en un lugar de la Mancha"?). Es difícil sustraerse a la fascinación de tanta coincidencia; su fuerza sugestiona, no sin motivo, y obliga a pensar en serio si no será, en efecto, una retahila de alusiones lopescas intencionalmente acumuladas. 
Con la negación no el sentido se va al polo opuesto, o sea, alejamiento o imprecisión u olvido; "no me quiero acordar" significa, pues, "no me viene ahora a las mientes esa persona o cosa, o no tiene para mi interés su recuerdo", etc. Estamos en esa explicación muy lejos de un contenido afectivo provocado por malas recordaciones.

Segundo: Cervantes pudo también emplear esa expresión como un recurso literario para dar interés a la novela. Este ocultismo se inició en los historiadores cuando, al narrar sucesos recientes o de personas vivas o de poco tiempo muertas, ocultaban los nombres en los relatos con frases como "cuyo nombre no es conveniente revelar", etc. De los historiadores pasa el giro a los novelistas, convertido en recurso literario para dar viveza a sus fábulas al aparentar engañosamente que trataban de hechos verdaderos cuyos personajes y lugares no era delicado descubrir: es cierto que la curiosidad del lector se aviva ante esa añagaza de darle como real lo que es pura invención. Cervantes recoge este recurso, empleado ya por Boccaccio, y con él empieza su obra para revestirla de una apariencia de historicidad (11). Durante toda la novela Cervantes se empeña en mantener esta apariencia: recuérdense los pormenores con que escrupuliza sobre la "verdad" de ciertos nombres, hechos y cosas, v. gr. al hablar del nombre "verdadero" del hidalgo; en esos momentos de fingimiento historicista suele el novelista añadir las expresiones "dicen, escriben los autores", como quien no hace más que recoger las historias escritas por autores próximos a los sucesos; y aquellas vacilaciones de crítica histórica "unos cuentan asi... mas otros añaden o cambian" etc. Por si fuera poco, toda la fábula está levantada sobre el supuesto autor Cide Hamete Benengeli, "autor de esta verdadera historia", a estilo de los libros de caballerías que se fingian escritos por sabios antiguos de nombres extravagantes y de fama conocidisima, aunque nadie los conocía.

Por todo esto se ve que Cervantes quiere, en plan más o menos burlesco, dar la impresión de que su personaje es histó76-84.

(11) Francisco Rodríguex Marin: ". . de cuyo nombre no quiero acordarme". En la Nueva Edición Critica del Quijote, T. IX, apéndice VI, pags. 
rico, y no novelado, hasta en los menores sucesos; en él este recurso, utilizado con un fingimiento que se destapa y descubre a sí mismo ante la burla continuada por nuevas apostillas sobre la "verídica historia", vierte sobre su novela una delicia de contraste, uno de tantos contrastes entre lo que es creado como maravillosa invención y lo que el autor simula narrar como hecho histórico, entre lo que vemos ser de imaginación desde el primer instante y lo que el autor aparenta querer ocultar pero que realmente destaca más con su inofensiva sátira. Así la frase, sobada en demasía, "en un lugar de la Mancha, de cuyo nombre no quiero acordarme", es el comienzo de la novela y el comienzo de su gracioso fingimiento.

Los dos sentidos examinados por Rodríguez Marín, la explicación gramatical y el recurso literario, pueden, $y$ aun deben, coadunarse y reforzarse mutuamente para la inteligencia del primer párrafo del Quijote.

Por su parte Astrana Marín, que da por cierto ser Esquivias "el lugar de D. Quijote", rechaza también toda interpretación sentimental; para él tanto el nacimiento novelístico del héroe "en un lugar de la Mancha", como el propósito del autor de no querer acordarse del mismo, se explican por el deseo de Cervantes de desviar la atención del lector del verdadero lugar de $D$. Quijote por motivos de delicadeza social e histórica (12). Ni siquiera existe el ocultismo sentimental, ya que, para este cervantista, Esquivias no fué ningún lugar de malas recordaciones para Cervantes; A. M. hasta reivindica a la esposa de Cervantes doña Catalina, de la pésima fama que tantos autores han echalo sobre ella (13).

\section{2) LA COORDENADA DEL TIEMPO: "no ha mucho tiempo que vivía..."}

Cervantes hace a $\mathrm{D}$. Quijote contemporáneo de su propia existencia. No debemos fiarnos gran cosa de la cronología cer-

(12) Astrana Marín: Obra y tomo citados, pág. 24 y sig.

(13) "La documentación destruye tan insensatas apreciaciones y tantasías (contra doña Catalina). A través de ella, las páginas de los protoculos cantan un himno a su abnegación, a sus virtudes de gran señora, a sus sacrificios, a su, constante amor por el esposo". Astrana Marin: Ob. y T. cit. paż 69. 
vantina en el Quijote, porque el autor se contradice a cada paso, $y$ aun parece no cuidarse mucho ni poco de ella. V. gr. al final del primer Quijote nos dice que la segunda parte estaba ya escrita por Cide Hamete; mas esto no impide que en el segundo Quijote se hable de cosas, hechos y personas muy posteriores a 1605, fecha del primer Quijote en que se daba ya por escrito el segundo.

Hecha esta salvedad, el hecho fundamental es que a D. Quijote se le hace contemporáneo de su inventor: si no bastara el ambiente típico de la época cervantina que se refleja en toda la obra, ahi están nombres, sucesos, libros, algunos de ellos rozando en su publicación el momento en que Cervantes los estampa en el suyo.

Esta consideración nos lleva de la mano a un problema muy grave en la génesis del Quijote: ¿ fué algún personaje real, contemporáneo o anterior a Cervantes, el que sugirió a éste su novela ? Con otras palabras: ¿ $D$. Quijote se copió de la realidad, fué la elaboración literaria de algún modelo vivo, de algún hidalgo del tiempo de Cervantes atacado de locura quijotesca, o de época anterior pero cuya memoria perduraba hasta llegar a los oídos de Cervantes?

Muy justamente advierte D. Luis Astrana Marin: "Sobre el tema de los modelos literarios y vivos de D. Quijote se han escrito miles de páginas, atestadas de yerros y disparates, con excepción de las muy doctas debidas a $D$. Marcelino Menéndez Pelayo y a D. Francisco Rodriguez Marín" (14).

(14) Astrana Marin: Ob. y t. cit., pág. 21.

Francisco Rodriguez Marín: "Los modelos vivos del $D$. Quijote de la Mancha" y "El modelo más probable del D. Quijote", ambos publ. en su col. "Estudios Cervantinos" ed. Atlas, Madrid, MCMXLVII, págs. 441-452 y j6!-572 respectivamente. El segundo estudio está también en su Nueva Edición Critica del Quijote, T. $X$, Apéndice $X L$, págs. 132-149, Ed. Atlas, Madrid, MCMXLIX.

Justo Carcía Soriano y Justo García Morales: "Los modelos vivos de D. Quijote", en su "Guia del lector del Quijote", antes cit. págs. 32-34.

Para Menéndex y Pelayo cita Astrana Marin su discurso "Cultura Literaria de Miguel de Cervantes y Elaboración del Quijote" (en "Estudios y Discursos de Crítica Histórica y Literaria", t. I págs. 323-356, según la Edición Nacional); pero en ese discurso el glorioso maestro no toca el tema de los "modelos vivos" de D. Quijote; sólo recoge algunos episodios de la época sobre la afición a los libros de caballerias. 
El asunto nos llevaría muy lejos. Para nuestro intento es suficiente advertir que, para identificar el modelo vivo de D. Quijote, si lo hubo, no hace falta buscar necesariamente un loco; basta un aficionado, exageradamente aficionado, a los libros caballerescos. $\mathrm{Ni}$ es forzoso hacerlo estrictamente contemporáneo de Cervantes, pues pudo ser anterior a él liegándole su noticia de oídas. Efectivamente, el modelo más probable que, al parecer, fué Alonso Quijada, de Esquivias, vivió entre el s. XV y el s. XVI, no fué propiamente loco y acabó fraile agustino.

El genio de Cervantes tomó el modelo y lo elaboró haciéndole pasar de la simple manía o exageración caballeresca a la verdadera locura; de esta forma el personaje se prestaba mejor a sacar de él todas las consecuencias, tanto de su carácter, en todo lo demás sano, como de esa parcela de su mente invadida por la locura caballeresca. El "no ha mucho tiempo que vivia" viene a extenderse a poco menos de un siglo; Alonso Quijada había sido sobrino del bisabuelo de la esposa de Cervantes (15).

\section{3) LA CONDICIÓN SOCIAL: \\ "un hidalgo..."}

¿Qué era un hidalgo, y cuál su condición social en tiempo de Cervantes?

La etimología de "hidalgo" es muy discutida y todavía no definitivamente aclarada: Menéndez - Pidal propone la más conocida, "filiu de aliquo" = "hijo de pro, de valía, hombre que tiene un valer heredado"; Américo Castro lo matiza como un calco del árabe, "ibn al-joms" = "fijo d'algo"; finalmente, con un !eonesismo problemático en su evolución fonética y en el origen histórico del tipo social, se ha pensado en "fideláticu" (16).

(15) Astrana Marin: Ob. y T. cit. págs. 21 y sig.

(16) Ramón Menéndez Pidal: "Cantar de Mio Cid. Texto, Gramática y Vocabulario". 3a. Edic., Espasa-Calpe, Madrid, 1954. Tomo 11, págs. 692 sigs. En la nota de la pág. 693 pueden verse otras etimologías ("italicu" "fijo del godo", céltico "fiddál").

Américo Castro: "En cuanto nos despojamos del prejuicio antiislámico, hijodalgo aparece como lo que es, como una de tantas formas de designar la condición de la persona a base de transcendencia mágica: el "hombre rico" es el "hijo de la riqueza" (ibn a!-dunyã)". De "España en su Historia", págs. 72 y sigs. Edit. Losada, Buenos Aires, 1948. 
El concepto social del hidalgo lo expresaba ya el Rey Sabio en sus Partidas cuando decía: "Hidalguía es la nobleza que viene a los hombres por linaje". Hidalgo era, pues, la "persona que por su sangre era de clase noble y distinguida". El elemento capital que distinguía la hidalguía de las otras clases nobles era ése que tan claramente aparece en las dos definiciones transcritas; era una nobleza que venía por sangre, por linaje. Hasta podemos decir que se trataba de un abolengo de la sangre, pues se requería, para ser hidalgo, heredar esa nobleza familiar desde los bisabuelos, o sea, durante tres generaciones seguidas.

Se distiguía perfectamente del caballero porque este título podía obtenerse por privilegio real con tal de poseer un caballo propio para la guerra y fortuna para mantenerlo por su cuenta; la hidalguía se obtenía por herencia de sangre y aun sólo por línea paterna. Con todo, avanzada la Edad Media, comenzaron a aparecer los hidalgos de privilegio que ganaban su hidalguía por cédula real (17).

Los derechos de los hidalgos eran de distinto orden, en general todos ellos encaminados a la tutela de su honra social. Tampoco eran escasos los deberes: su cumplimiento requería del hidalgo una renta de 500 sueldos aproximadamente. No todos poseían esa fortuna, y entonces no les cabía otro remedio que reducirse al estado de villano (para lo que se seguía una ceremonia que hoy nos resulta sumamente graciosa y rudimentaria) o reducirse a vivir en la mayor estrechez económica empleando el poco dinero en esas obligaciones sociales (18).

(17) Más datos y noticias sobre los hidalgos pueden leerse en el articulo "Hidalgo" de la Enciclopedia Espasa-Calpe, T. 27, págs. 1377-1380.

(18) "El hidalgo que cayese en pobreza, podía, si quería, tornarse villano. El Fuero Viejo establece el procedimiento para ello: debía irse a la lglesia y decir en Concejo: "Sabed que quiero ser vuestro vecino en infurción y en toda facienda vuestra": y pasando tres veces bajo una aguijada puesta sobre el cuello de dos hombres exclamar: "Dejo nobleza y tórnome villano"; y desde aquel momento él y los hijos e hijas que tuviere eran villanos. Mas una vez asi dejada la hidalguia, podía recobrarse, con igual procedimiento, manifestando ante el Concejo: "Dejo vuestra vecindad, pues no quiero ser vuestro vecino": pasando sobre la aguijada, diciendo: "Dejo villania y tomo nobleza"; y cuan. tos hijos e hijas hiciere "tendrán quinientos sueldos y serán nobles". (Ley 16. Tit. 5..$^{\circ}$ Lib. 1. ${ }^{\circ}$ ). La hidaiga (dueña hijadalgo) que casase con labrador, se volvia villana y sus hijos e hijas eran villanos; pero muerto el marido podía reco. 
La tranformación social que afecta al organismo medieval al llegar la Edad Moderna, da de lleno en los hidalgos: vivían éstos, en buena parte, de la milicia tal como en la Edad Media estaba organizada; su situación militar era verdaderamente privilegiada. La nueva estructura del ejército, su reclutamiento y su jerarquización en la Edad Moderna, les hizo perder automáticamente esos privilegios y los dejó desamparados. Los Reyes Católicos advirtieron el peligro que se cernía sobre los hidalgos, y con su proverbial visión de los problemas sociales, se preocuparon por que no quedasen dislocados; les fueron abiertos generosamente los caminos de la magistratura y en ellos muchos supieron defenderse ante la nueva situación social. Mas otros o no quisieron o no pudieron acogerse a esa providencia; los tales, si no se hacían clérigos o no poseían dineros bastantes, se hallaban con las manos vacías y tenían que refugiarse a sus aldeas iolariegas a ocultar su pobreza y su verguienza. En sus solares eran respetados y honrados; mas, si las rentas no daban para más, tenian que pasarse hambres ocultas y atroces. Son los llamados hidalgos de aldea; si la hacienda era escasa, se les decía hidalgos de cuna pobre; el grado más precario lo representaban los hidalgos de gotera que sólo gozaban de sus privilegios en su lugar, perdién. dolos al mudar el domicilio.

La crisis económica de estos hidalgos de aldea se acentúa a medida que el desarrollo de la Industria y el Comercio desvalora cada vez más la renta de tierra; los hidalgos de cierta hacienda veían asi disminuirse sus ingresos y declinar hacia el abismo de la pobreza. Les cabía una solución; dedicarse a trabajos lucrativos, a negocios; pero ellos de ningún modo daban su brazo a torcer en este punto por considerar esos negocios como propios de villanos; el desajuste, la inadaptación al nuevo ambiente aumentaba entre ellos. No pudiendo entregarse a ese mester noble que son las armas, prefieren su pobreza antes que ganarse la vida con medios no honrados, según el concepto o pre-

brar la hidalguia, tomando una albarda, yendo a la tumba del marido y golpeando ésta con aquélla tres veces, diciendo en cada una: villanía y dame mi hidalguia" (Ley 17, Lib. 1. $)^{\prime}$ ". Tomado del Art. "Hidalgo" de la Enciclop. Espasa-Calpe, págs. 1379-1380. 
juicio que ellos tenían de oficio honrado; " hidalgo honrado, antes roto que remendado", era proverbio entre la hidalguía.

Es el momento en que la miseria comienza a cebarse de forma alarmante en los hidalgos, "mártires ocultos y nunca confesores de su pobreza", según la expresión jocosa de Rodríguez Marín. Siempre hubo hidalgos pobres, pero nunca tantos como en la Edad Moderna en que el hidalgo pobre, honrado y celoso de su sangre pero consumido de miserias mal disimuladas, vino a ser un verdadero tipo social con rasgos bien definidos: orgullo y hambre, o como se dijo "orgullo y pobreza, todo en una pieza" (19).

Y éste es también el momento en que esa miseria, en contraste con el orgullo, se convierte en pábulo de las burlas de las gentes: chistes y refranes populares se amontonam sobre estos infelices hidalgos de cuna pobre; en ellos se ridiculiza esa paradoja social de orgullo y pobreza, aprovechada por el bajo pueblo para vengarse del desprecio con que era mirado por los hidalgos. "Hidalgo es D. Juan como un gavilán, mas no hay pan"; (que recoge el dicho "hidalgo como el gavilán"). "Hidalgo, hidegalgo", etc. etc. Quiñones de Benavente en su entremés "El Aceitunero", resumía esta paradoja y esta burla popular de los pobres hidalgos:

\section{Tiene el hidalgo de aldea}

\section{mucha sangre y poco sebo.}

Antes, y con más incisiva malicia, habían caído sobre la pobreza de los hidalgos dos espíritus de uñas, Góngora y Quevedo; espiguemos dos ejemplos de cada uno (20):

(19) Lo mejor sobre el tema es el articulo del gran maestro cervantista D. Francisco Rodriguez Marín: "La pobreza de los hidalgos" en su Nueva Edición Crítica del Quijote. T. X. Ap. XXXVI, págs. 90-101, del que tomo varias notas.

(20) Citamos a Cóngora por sus "Obras Completas" publicadas por Juan e Isabel Millé y Giménez, en la Ed. Aguilar. Madrid, 1952.

Las citas de Quevedo las damos por la edición crítica de Luis Astrana Marin (VERSO), de la misma Ed. Aguilar. Madrid, 1952. 
De Góngora: Estáse el otro don Tal

desde las doce a las trece

rezando aquella oración

de la mesa sin manteles,

y sálese luego al barrio

escarbándose los dientes

con un falso testimonio,

por el decir de las gentes.

(Romances, 31, pág. 109)

\begin{abstract}
Al pobre pelafustán
que de arrogancia se paga,

y presenta la bisnaga (21)

por testigo del faisán,

viendo que las barbas dan

testimonio de las migas. . .
\end{abstract}

(Letrillas, 106, pág. 303)

De Quevedo: Su caudal es bizarría

y por lo bravo le llama

al dormir león sin cama

$y$ al comer cama-león...

(Poesías Satíricas, IV, pág. 84)

(21) Biznaga: la R. Academia define este vocablo en su'segunda acepción: "cada uno de los piececillos de las flores de esta planta (la biznaga), que se emplean en algunas partes para mondadientes". Góngora lo usa para efectos burlescos contra los mal encubiertos hambrones; al ejemplo transcrito arriba añádase éste otro:

$$
\begin{aligned}
& \text { Que se precie un don Pelón } \\
& \text { que se comió un perdigón, } \\
& \text { bien puede ser: } \\
& \text { mas que la biznaga honrada } \\
& \text { no diga que fué ensalada, } \\
& \text { no puede ser. }
\end{aligned}
$$

(Letrillas, 95, pág. 286)

Huelga esclarecer en boca de qué tipo social pone Góngora este mondadientes de la biznaga: en aquel pelafustán (definido por la R. Ac. como "persona holgazana, perdida y pobretona") y en este Don Pelón (con su título de máscara y su "peladura" de fondo). la "honradez" de la biznaga está señalando el doble semblante del hidalgo y su comparsa.

De la misma casta el Don Tal del Romance 31, copiado en el texto, que se salia por los barrios "escarbándose los dientes con un falso testimonio" que no debía ser tan "honrado" como la biznaga. 
Que el hidalgo por grandeza

muestre cuando riñe a solas

en la multitud de olas

tormentos en la cabeza;

que disfrace su pobreza

con rostro grave y sereno,

bueno.

Mas que haciendo tanta estima

de sus deudos principales,

como las ollas nabales,

como batalla marina;

que la haga cristalina

a su capa el pelo ralo,

malo.

(Poes. Sat., XXI, pág. 95)

Como Quiñones de Benavente, como Góngora, como Quevedo, la literatura de todos los géneros se apodera de ese tipo y de ese ambiente burlesco y hace del hidalgo un tópico literario; el género satírico se ensaña en los hidalgos pobres desde mediados del XVI y su figura se caricaturiza cada vez más, hasta la exageración en la época de los Felipes. Desde la picaresca, ya en su primera obra (22), hasta los "Sueños" de Quevedo, atravesando el Teatro, y la Poesía, el hidalgo pobre va paseando su triste y vano orgullo de sangre, su negra honrilla, esa "honra espantadiza" que dice Cervantes, su vagancia y su necesidad. Podía no comer o comer mal, pero no podía faltarle el palillo de dientes que sintetizaba para el público la situación precaria de esa hidalguía de

(22) El tipo de hidalgo pobre, con todos sus rasgos caricaturescos, está ya perfectamente dibujado en ese escudero que es el segundo amo de Lazarillo; su estampa nos muestra cómo ya a mediados del XVI el tópico literario del hidaigo orgulloso y hambriento comenzaba a rodar por los libros completamente definido. Ese capítulo del Lazarillo de Tormes sobre el escudero es, además, de sumo interés, porque en él se dan la mano y conviven amigablemente las dos contrafiguras clásicas del hambre - el hidalgo pobre y el pícaro - cada una con su problemática y su solución, tan diferentes. Probablemente no hay otro caso en que las dos caricaturas (llámolas asi porque ambas desbordan evidentemente las líneas de lo real y, a ratos, hasta de lo verosímil) se enlacen tan humanamente, sobre todo a través de la comprensión y compasión del picarillo que "gana" para dar de comer a su amo al que cobra cariño a pesar de su negra honrilla, tan ridicula como inofensiva. 
hambre. Sobre el palillo de dientes, instrumento inocuo del disimulo del hambre de los hidalgos pobres, cayó tambien la saña de los burladores, acumulando los apodos ridículos, entre los que sobresale, por su divulgación y jocosidad, el de falso testimonio (23).

La literatura clásica abusó de ese tópico literario porque sabía muy bien que todo lo que por alli se echase sería bien recibido por el pueblo que desahogaba con sus carcajadas un complejo de inferioridad; de esa actitud del vulgo se aprovechaban todos, particularmente los autores de teatro, dedicados a un género literario que, al menos entonces, era el de contacto más directo con el pueblo (24).

Mas, por tratarse de un tópico, de un lugar común, hay que poner mucha sordina a esa fama de hambrientos orgullosos que ha caído sobre los hidalgos; ni había tantos hidalgos pobres, ni era tan extremada su pobreza como podría deducirse de las burlas literarias. Acontece con el hambre de los hidalgos lo que con la

(23) Con razón afirma Rodríguez Marín que "sobre el palillo de dientes podria escribirse, a poco trabajo, una interesante monografía: tantas son las noticias que de él y de su ostentoso empleo nos han quedado. ("La pobreza de los hidalgos", artículo citado en la nota 19; véase también sobre el tema nuestra nota 21).

(24) Cervantes mismo ayuda, y no con granitos de arena, a levantar ese monumento al hambre de ciertos tipos clásicos. Pasamos de largo su picaresca porque es harto conocida. Para la hidalguía, dando de lado a su máxima criatura, (que al cabo, si no nadaba en delicias, porque era pobre, tampoco se consumía en la miseria), basten dos botones de muestra. Uno es del cap. XLVI de la segunda parte del Quijote; habla Benengeli, ol supuesto autor del Quijote: "Tú, segunda pobreza (que es de la que yo hablo), por qué quieres estrellarte con los hidalgos y bien nacidos más que con la otra gente? ... Miserable del bien nacido que va dando pistos a su honra, comiendo mal y a puerta cerrada, haciendo hipócrita al palillo de dientes con que sale a la calle después de no haber comido cosa que le obligue a limpiárselos! Miserable de aquél, digo, que tiene la honra espantadiza y piensa que desde una legua se le descubre el remiendo del zapato, el trasudor del sombrero, la hilaza del herreruelo y la hambre de su estómago!" El otro es de la comedia "La Gran Sultana", jornada III:

En un bajel de diez bancos,

de Málaga, y en invierno,

se embarcó para ir Orán

un tal Fulano de Oviedo,

hidalgo, pero no rico:

maldición del siglo nuestro,

que parece que el ser pobre

al ser hidalgo es anexo. 
de los picaros; los críticos confunden lo que era un tipo literario, de base real pero estilizada, y por tanto de rasgos exagerados, caricaturados, con to que era el tipo real común, tanto en los hidalgos como en los pícaros. Son justas las protestas de ciertos autores como Salcedo, Gonzáles Palencia (25) y otros, contra los que han osado hacer estudios sociales y económicos de esas clases auxiliándose de las ponderaciones satíricas de escritores clásicos.

Para nosotros to interesante es que existía el tipo real y que al mismo tiempo existía el tipo literario creado en parte por el refrán popular $y$ en parte por los escritores satíricos.

El hidalgo que va a crear Cervantes es un modelo de hidalgo de aldea de rasgos equilibrados; pobre, pero no famélico; celoso en extremo de su honra, pero accesible y manso con los humildes aldeanos; inteligente, culto, varón a carta cabal de corazón y de mente; en fin, un hidalgo que era bastante corriente entre los de su época, pero al que una ingeniosa locura, precisamente del orden de la honra y del más valer, coloca por encima de cuantos hidalgos reales o imaginarios hubo ni habrá jamás, gracias a la buena estirpe, a la buena sangre de su padre, y no padrasto (como él se llama a si mismo en el prólogo del primer Quijote,), el linaje que Cervantes le legaba desde su poderoso ingenio y su humanísimo corazón.

(Continúa)

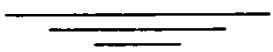

(25) Angel Salcedo: "Literatura Española", T. II, págs. 105 y sigs., Madrid, $1915-17$.

Juan Hurtado y Angel Conzález - Palencia: "Historia de la Literatura Española". págs. 357-358, 6a. edic. Madrid, 1949. 